\title{
Web Third-Person Effect Hypothesis: Do likes and Shares Affect Users' Perceptions?*
}

\author{
Nikos Antonopoulos, Dimitrios Giomelakis, Andreas Veglis, Antonis Gardikiotis \\ Media Informatics Lab, Thessaloniki, Greece \\ Aristotle University of Thessaloniki, Thessaloniki, Greece \\ Charalampos A. Dimoulas \\ Laboratory of Electronic Media, Thessaloniki, Greece \\ Aristotle University of Thessaloniki, Thessaloniki, Greece
}

\begin{abstract}
This paper studies the web third-person effect (WTPE) hypothesis in the context of news websites and social media. Specifically, the study examines the role of social media metrics (i.e., shares and likes of news articles) in shaping users' opinion about the websites. Users' news sharing intention in social media is also investigated. Based on a structured online questionnaire $(N=7,404)$, the results confirm that WTPE can be found in social media metrics without the presence of specific message content. It should be noted that the effect was found at three perceptual levels, self, friends, and other users. Regarding intention for news sharing, text was indicated as the most important reason among Internet users. Finally, the work demonstrates significant correlations between WTPE and article characteristics that influence people's attitudes to share news online.
\end{abstract}

Keywords: web third-person, Facebook, share, like, social media metrics

\section{Introduction}

Internet has become an integral part of the modern society and many people nowadays use it for several purposes, such as information, entertainment, interpersonal utility, passing time and convenience (Papacharissi $\&$ Rubin, 2000). Website quality, credibility or interactivity attract users' attention, thus influencing the degree of their engagement (Antonopoulos \& Veglis, 2012; Flanagin \& Metzger, 2007; Kuan, Bock, \& Vathanophas, 2008; Rocha, 2012). Web 2.0 and new Internet technologies are characterized by a new "architecture of participation", which supports the co-production of information, social networking, sharing and rich user experiences (Barassi \& Trere, 2012; O'Reilly, 2005). Intimately related to Web 2.0 is user-generated content

\footnotetext{
* The authors received no financial support for the research and for authorship of this article.

Nikos Antonopoulos, Phd, MSc, BSc, Postdoctoral Researcher, Media Informatics Lab; School of Journalism \& MC, Aristotle University of Thessaloniki.

Dimitrios Giomelakis, PhD Candidate, Media Informatics Lab; School of Journalism \& MC, Aristotle University of Thessaloniki.

Andreas Veglis, Phd, MA, BSC, Professor, Media Informatics Lab; School of Journalism \& MC, Aristotle University of Thessaloniki.

Antonis Gardikiotis, Assistant Professor, Media Informatics Lab; School of Journalism \& MC, Aristotle University of Thessaloniki.

Charalampos A. Dimoulas, Dr. Eng., Assistant Professor, Laboratory of Electronic Media; School of Journalism and Mass Communications, Aristotle University of Thessaloniki.
} 
(e.g., blogs, posts or tweets) often made available via social media websites. The proliferation of social media during the last decade has introduced a more active (and interactive) internet usage that satisfy various socio-psychological aspects, such as showing affection, the need to vent negative feelings, social connection, recognition as well as entertainment, information needs and cognitive requirements (Yoo, 2012; Giannakos, Chorianopoulos, Giotopoulos, \& Vlamos, 2013; Leung, 2013; Wei, Lin, Lu, \& Chuang, 2015; Yu, 2016). These new web technologies have a significant impact on journalism and its relation to the audience (Goode, 2009). The so-called new media alter the narrative news industry into a more database-like information source, allowing at the same time several channels of feedback and dialogue (Giomelakis \& Veglis, 2015; Kluver, 2002). In this context, there is a rise of active "produsage" (a contraction of production and usage) that blurs the boundaries between passive consumption (users) and active production (producers) (Bruns, 2008).

In recent decades, a large body of research has been devoted to the investigation of the perceived influence of media (Henriksen \& Flora, 1999; Lo \& Wei, 2002; Jinadasa, 2009). In this context, the Third-Person effect (TPE), which was initially presented by Davison (1983) and is associated with users' media consumption, has been extensively studied in traditional media (Eveland et al., 1999). According to the initial theory, people tend to believe that mass communicated media messages have a greater effect on others than on themselves. However, due to the continuous advances in Web technologies and the richer user experiences they provide, it is time to explore how individuals view the impact of social media. To the best of our knowledge, there is significantly less research with respect to TPE and web media and this may be due to the fact that it is a relatively new research field ( $\mathrm{Li}, 2008)$. In this case and because of the focus on Web media, the term Web Third-person effect (WTPE) has been adopted. Over the last decade, WTPE has been researched in social media contexts, social media metrics and also across online news (Banning \& Sweetser, 2007; Schweisberger, Billinson, \& Chock, 2014; Stavrositu \& Kim, 2014; Tsay-Vogel, 2015). Nevertheless, further studies need to be conducted in this field where the viewer is able to affect media content. The current study was designed as an extension to prior work where WTPE was found and analyzed in structural aspects of the information on media websites (Antonopoulos et al., 2015). In response to the limited literature dealing with TPE and new media, the present paper extends this line of research in the context of online news and social media by examining the role of social media metrics in shaping users' opinion about the websites and, consequently, WTPE as well as users' news sharing intention in social media.

\section{Social Networks and Information Sharing Motives}

The process of sharing digital content can be characterized as the fundamental and constitutive activity of Web 2.0. In brief, it has become the word of choice to describe the way people participate in Web 2.0, including both the processes of distribution and communication (John, 2012). Undeniably, modern websites need to be designed in order to facilitate sharing of information (Chen, Yen, \& Hwang, 2012) and in this context, social buttons constitute key features that allow online users to recommend, share, like or bookmark content in various social media platforms. These buttons make easier the cross-syndication of web content, introducing a user-centered approach to the recommendation and the creation of links among web objects (Gerlitz \& Helmond, 2013). In order to be attractive to their audience, Web media integrate social media aspects to build brand trust (Habibi, Laroche, \& Richard, 2014) and consider its users' recommendations (Knobloch-Westerwick et al., 2005). The new features along with the so-called "Like economy" contribute to the instant conversion of user engagement into numbers on button counters (Gerlitz \& Helmond, 2013). 
Diverse popularity metrics can affect user's perceptions of content credibility (Westerman et al., 2012), as well as selective exposure to online news (Knobloch-Westerwick et al., 2005).

It is worth mentioning that the majority of the previous research on social media was focused on information sharing generally and not specifically in news sharing. In this context, the nature of news content, its special characteristics as well as prior social media experience are factors that should be taken seriously into consideration. By incorporating the user's experience perspective, Lee and Ma (2012) revealed that previous social media sharing experience and socializing were the two most prominent factors, which influence news sharing intention in social media. Gratifications of information (seeking) and status seeking were also proven strong motivating factors. In this context, feedback to articles may depend on the appeal of the article rather than the topic per se (Bastos, 2014). Studying the news processes related to the use of Facebook, Bro and Wallberg (2014) revealed that two factors were particularly important in understanding the news stories that audiences receive: actors and actions. The former refers to well-known persons or places, while the latter pertains to something out of the ordinary. In another relevant study, informativeness was the strongest motivation regarding news sharing intention in social media, followed by socializing and status seeking (Lee, Ma, \& Goh, 2011). Finally, social media users tend to favor hard news (opinion pieces, national and world news) over soft and general news (Bastos, 2014). To sum up, the new features provided by social media have the potential to change the nature of news sharing. Given that, news sharing in social media has become a phenomenon of growing social, economic and political significance (Lee \& Ma, 2012).

\section{Third-person Effect and the Web}

The Third-person effect (TPE) (Davison, 1983) is based on the assumption that individuals tend to perceive that messages from a media source have a greater effect on others (third person) than on themselves (first person). Since its initial proposal, the theory has been widely accepted in communication science, attracting significant attention in academia. Specifically, scholars have studied and repeatedly confirmed this phenomenon in many areas, such as advertising, news or political communication and online marketing (Hoffner et al., 1999; Rucinski \& Salmon, 1990; Zhang \& Daugherty, 2009). It should be noted that TPE appears on all typical media regardless the method employed, the observed content, the medium under study, the flow of questions, and the phrasing or the quality of the message (Perloff, 1999). Regarding digital media, Web-Third person effect (WTPE) (Antonopoulos et al., 2015) can be detected across blogs, online newspapers (Banning \& Sweetser, 2007), online news in social media contexts (Schweisberger et al., 2014), social media metrics (number of shares and comments) in the process of opinion formulation about health information (Stavrositu \& Kim, 2014), among Facebook users (Tsay-Vogel, 2015) and finally in structural aspects of the information on media websites (Antonopoulos et al., 2015) (see Table 1). A significant part of the research on TPE has focused on the perception of negative media content. TPE seems to be clearer when a negative or controversial message is involved, such as pornography (Lo \& Wei, 2002), political propaganda, smoking advertisements (Henriksen \& Flora, 1999; Wei \& Lo, 2007) or reports about violence (Hoffner et al., 1999).

Social influence seems to play a role in choosing news content. People tend to prefer articles, which appear to be appreciated and selected by a large number of other users (Sundar \& Nass, 2001) and also, they want to be informed about social reality from other members of the social groups they belong to (Neuman, Just, $\&$ Crigler, 1992). This may also have an impact on the audience involved, in the number of the involved users, in the corresponding news-related social media (i.e., the number of followers on Twitter), an issue that is 
further associated with perceived credibility (Westerman et al., 2012). Users' observations of such published content function as feedback through recommendation-ratings procedures (Lee, 2012) adding at the same time value to the content, thus influencing ourselves and others (Stavrositu \& Kim, 2014).

An important parameter to third person perception regards the social closeness between the compared targets: the social distance between self and others, when estimates of media effects are made, is grounded on the observed dissimilarities between self and the compared others (Eveland et al., 1999), which has been found to be a key factor that moderates third person effect (Tewksbury, 2002). Given that, many studies tend to use comparison groups of increased similarity (self, ingroup and others) with regard to TPE (Gardikiotis, 2008). It should be mentioned that the present work employs the same groups (friends and others), following the work of Brosius and Engel (1996). Demographic variables, such as age or education (Tiedge et al., 1991; Meyrick, 2001) were also found to be connected to TPE, something that this study examines as well. Nevertheless, in several other research works age or demographic variables were not found to contribute significantly to TPE (Henriksen \& Flora, 1999; Salwen \& Dupagne, 2001).

Table 1

Previous Research Papers on Web Third-person Effect

\begin{tabular}{|l|l|l|l|l|}
\hline Reference & Scope & Media sources & Grouping structure & Supported WTPE hypotheses \\
\hline $\begin{array}{l}\text { Banning and } \\
\text { Sweetser (2007) }\end{array}$ & $\begin{array}{l}\text { Investigating WPTE in the } \\
\text { medium or the messenger } \\
(N=145)\end{array}$ & $\begin{array}{l}\text { Personal blogs, media } \\
\text { blogs, online and print } \\
\text { newspapers }\end{array}$ & Self and others & $\begin{array}{l}\text { Relevancy of the message } \\
\text { orientation. Independency of } \\
\text { the medium }\end{array}$ \\
\hline $\begin{array}{l}\text { Schweisberger, } \\
\text { Billinson, and } \\
\text { Chock (2014) }\end{array}$ & $\begin{array}{l}\text { Investigation of perceived } \\
\text { message influence and } \\
\text { WTPE }(N=88)\end{array}$ & Facebook & $\begin{array}{l}\text { WTPE dependency by the } \\
\text { news stories relevancy, } \\
\text { quality and the supported } \\
\text { medium (Facebook })\end{array}$ \\
\hline $\begin{array}{l}\text { Stavrositu and Kim } \\
(2014)\end{array}$ & $\begin{array}{l}\text { Investigation of the } \\
\text { impact regarding the } \\
\text { number of shares and } \\
\text { comments on WTPE } \\
(N=144)\end{array}$ & Professional news blog & Self and others & $\begin{array}{l}\text { With single story and context. } \\
\text { Cancer risk news story } \\
\text { interact with social media } \\
\text { metrics. The conveyed story } \\
\text { and the relevant social media } \\
\text { metrics influence WTPE }\end{array}$ \\
\hline $\begin{array}{l}\text { Antonopoulos } \\
\text { et al. (2015) }\end{array}$ & $\begin{array}{l}\text { Investigation of WTPE for } \\
\text { user generated } \\
\text { information }(N=9,150)\end{array}$ & $\begin{array}{l}\text { All types of media } \\
\text { websites }\end{array}$ & $\begin{array}{l}\text { Evidence of WTPE regarding } \\
\text { the number of users being } \\
\text { concurrently online, the exact } \\
\text { number of users having read } \\
\text { each article and the number of } \\
\text { shares in social media }\end{array}$ \\
\hline Tsay-Vogel (2015) & $\begin{array}{l}\text { Investigating WPTE } \\
\text { among Facebook users } \\
(N=375)\end{array}$ & Facebook & $\begin{array}{l}\text { Support for WTPE in the } \\
\text { context of social media. Users } \\
\text { tend to report stronger effects } \\
\text { of Facebook on other users } \\
\text { and less on themselves }\end{array}$ \\
\hline
\end{tabular}

\section{Hypotheses}

This paper extends research of WTPE by studying the phenomenon in the context of news websites and by using social media metrics. Specifically, respondents are asked whether they think that the number of shares that an article has in social networks can affect themselves, their friends and others' opinion about the specific website. Another objective concerns the reasons (i.e., article characteristics) that usually drive users to post (share-like) a news article on social networks. Possible correlations between article characteristics and WTPE are also examined. 
Following the preceding discussion the study's hypotheses and research questions are as follows:

H1: Following the WTPE reasoning it is expected that participants will think that the number of posts (i.e., the information of the number of users that have posted the article on Facebook, Twitter or other social media) will affect more their friends' and others' opinions about the website as compared to themselves (hereafter, it will be referred as social posting).

H1A: The WTPE is expected to depend on social distance: self will be perceived to be less influenced compared to friends and others, and friends compared to others.

H1B: The WTPE will be evident, irrespective of the messagecontent (positive or negative).

H1C: The WTPE will depend on article's characteristics (i.e., content type of the article, article popularity, kinds of reproduction from different users' profiles/attributes).

RQ: Specific article characteristics will be perceived to drive people to post (share-like) in social media, such as: the presence of an interesting picture (denoted as social1), or an interesting video (social2), whether the article has been posted by their friends (social3) and whether others have posted it (social4), the perceived interest of the text (social5), or something else (social6).

Previous research has demonstrated the WTPE in Greek media websites regarding the characteristics that users observe when visiting a media website (Antonopoulos et al., 2015). The sample from this previous study $(N=9,150)$ was also employed in the current work (with exclusion criteria that apply to this paper, $N=6,998$ ) in order to enhance the results and provide new knowledge regarding the article characteristics that drive people to post an article in social media (RQ).

\section{Method}

\section{Pilot Study}

Based on the relevant theory, an initial version of the online questionnaire was developed. A pilot research was conducted with fifteen experts in the topics of statistical analysis, human computer interaction, psychology, human behavior, computer science, journalism, graphic designing, communication and media websites, who were asked to complete the survey and provide feedback. A number of adjustments were made on the initial questionnaire, mainly in the fields of readability and usability, leading to the necessary corrections and improvements before finalizing it.

\section{Measures and Procedure}

Based on the pilot study's findings a survey using a structured online questionnaire was conducted in order to explore the research hypotheses and questions. Data collection took place from January to May 2014. The online questionnaire consisted of questions regarding WTPE (Antonopoulos et al., 2015), along with other demographic information. All questions, except age, continent they live in, currency they pay their bills, and if they have an account at a social network (Yes or No) were answered on a five-point scale, with the higher values representing positive response or agreement.

A primary goal in the process of the study was to include different types of samples (three in Greek and one in English language). Initially the survey was conducted early in 2014 with the participation of sixty-six undergraduate and postgraduate students (computer laboratory sample). Subsequently, the same questionnaire was posted online on a Greek media website for a period of three weeks. In March of 2014, the questionnaire was translated in English (questions concerning respondents' continent and the currency in which they pay their 
bills were added). The English language questionnaire was initially completed by 20 Erasmus students via e-mail and it was also posted in different groups on Facebook (over 10) dealing with educational fields (overall, the groups had approximately over 700,000 members at the time of the study). That study was online for three weeks, in the period of April to May 2014. Finally, as previously mentioned, the sample $(N=9,150)$ of a previous research (Antonopoulos et al., 2015) was also used in order to study this time the effect concerning the reasons (i.e., article characteristics) that users post (share-like) an article in social media.

All participants were firstly informed about the purpose of the study, and then they provided their consent to participate in the online survey, while full anonymity and confidentiality were primary prerequisites (the survey followed all the ethical and institutional guidelines).

\section{Profile of Participants}

In order to investigate further the WTPE and the reasons that the readers post (share-like) an article from websites to social media, four samples were tested. In the online survey the participants (four samples with same questions) answered questions regarding their gender, their personal monthly income regardless of its source (work, parents, bonus, etc.) and their educational background. All participants were initially asked to report how often they use the Internet, by selecting one of the five categories ((1) Once a month, (2) Once a week, (3) 2-3 times a week, (4) 4-5 times a week, and (5) Daily). Furthermore, all participants were asked to indicate if they have any social network account (i.e., Facebook, Twitter, LinkedIn, Hi5, Academia, etc.) by selecting Yes or No.

Table 2

Participants' Demographics for Gender, Income, and Education (Computer Laboratory Sample)

\begin{tabular}{llcc}
\hline Factors & Answers & Frequency & Percentage $(\%)$ \\
\hline Gender & Female & 50 & 75.8 \\
& Male & 16 & 24.2 \\
Monthly income (euros) & Total & 66 & 100 \\
& $0-400$ & 49 & 74.2 \\
& $401-800$ & 14 & 21.2 \\
& $801-1,200$ & 2 & 3 \\
Education & $1,201-1,600$ & 1 & 1.5 \\
& $1,601-2,000$ & 0 & 0 \\
& $2,001+$ & 0 & 0 \\
& Total & 66 & 100 \\
& Elementary & 0 & 0 \\
& Junior high school & 0 & 0 \\
& High school & 0 & 0 \\
& Student & 51 & 77.3
\end{tabular}

The first questionnaire (i.e., the computer laboratory sample) was answered by 66 participants (see Table 2) with age ranging from 18 to 24 years old $(M=22 ; S D=4.571)$. The participants were fluent in Greek language. 
The second Greek questionnaire was posted online on a mass media website. The survey was answered by 68 adults (see Table 3 ) with a unique IP address and with age ranging from 18 to 57 years old $(M=30.91$; $S D=10.10)$.

Table 3

Participants' Demographics (Gender, Income and Education-Mass Media Website Sample)

\begin{tabular}{llcc}
\hline Factors & Answers & Frequency & Percentage (\%) \\
\hline Gender & Female & 38 & 55.9 \\
& Male & 30 & 44.1 \\
Total & $0-400$ & 68 & 100 \\
& $401-800$ & 26 & 38.2 \\
& $801-1,200$ & 17 & 25 \\
& $1,201-1,600$ & 15 & 22.1 \\
& $1,601-2,000$ & 4 & 5.9 \\
Education & $2,001+$ & 5 & 7.4 \\
& Total & 1 & 1.5 \\
& Elementary & 68 & 100 \\
& Junior high school & 0 & 0 \\
& High school & 0 & 0 \\
& Student & 11 & 16.2 \\
& Graduate & 19 & 27.9 \\
& Master's degree student & 29 & 42.6 \\
& Master's degree graduate & 1 & 1.5 \\
& Phd candidate & 8 & 11.8 \\
& Phd holder & 0 & 0 \\
& Total & 0 & 68 \\
\end{tabular}

The third questionnaire (English language) was answered by 272 adults (see Table 4) with a unique IP address and with age ranging from 18 to 57 years old $(M=33.11 ; S D=10.29)$.

Table 4

Participants' Demographics for Gender, Income, Education, Continent, and Currency (English Sample)

\begin{tabular}{llcc}
\hline Factors & Answers & Frequency & Percentage $(\%)$ \\
\hline Gender & Female & 151 & 55.5 \\
& Male & 121 & 44.5 \\
& Total & 272 & 100 \\
Monthly income & $0-400$ & 54 & 19.9 \\
(currency of the participant) & $401-800$ & 52 & 19.1 \\
& $801-1,200$ & 34 & 12.5 \\
& $1,201-1,600$ & 30 & 11 \\
Education & $1,601-2,000$ & 19 & 7 \\
& $2,001+$ & 83 & 30.5 \\
& Total & 272 & 100 \\
& Elementary & 0 & 0 \\
& Junior high school & 1 & 0.4 \\
\hline
\end{tabular}


(Table 4 continued)

\begin{tabular}{|c|c|c|c|}
\hline Factors & Answers & Frequency & Percentage $(\%)$ \\
\hline \multirow[t]{6}{*}{ Education } & Graduate & 51 & 18.8 \\
\hline & Master's degree student & 28 & 10.3 \\
\hline & Master's degree graduate & 60 & 22.1 \\
\hline & Phd candidate & 53 & 19.5 \\
\hline & Phd holder & 40 & 14.7 \\
\hline & Total & 272 & 100 \\
\hline \multirow[t]{7}{*}{ Continent } & Europe & 182 & 66.9 \\
\hline & North America & 37 & 13.6 \\
\hline & South America & 8 & 2.9 \\
\hline & Africa & 9 & 3.3 \\
\hline & Asia & 28 & 10.3 \\
\hline & Oceania & 8 & 2.9 \\
\hline & Total & 272 & 100 \\
\hline \multirow[t]{13}{*}{ Currency } & Euro & 124 & 45.6 \\
\hline & US dollar & 38 & 14 \\
\hline & UK pound & 28 & 10.3 \\
\hline & Canadian dollar & 4 & 1.5 \\
\hline & Australian dollar & 9 & 3.3 \\
\hline & New Zealand dollar & 0 & 0 \\
\hline & Yen & 0 & 0 \\
\hline & Pakistani Ruppe & 2 & 0.7 \\
\hline & Indian Ruppe & 8 & 2.9 \\
\hline & Renminbi (yuan) & 0 & 0 \\
\hline & Peso & 1 & 0.4 \\
\hline & None of the above & 58 & 21.3 \\
\hline & Total & 272 & 100 \\
\hline
\end{tabular}

Table 5

Participants' Demographics for Gender, Income and Education (Greek Media Websites Sample)

\begin{tabular}{llcc}
\hline Factors & Answers & Frequency & Percentage $(\%)$ \\
\hline Gender & Female & 4,474 & 63.9 \\
& Male & 2,524 & 36.1 \\
Total & $0-400$ & 6,998 & 100 \\
(euros) & $401-800$ & 3,276 & 46.8 \\
& $801-1,200$ & 1,547 & 22.1 \\
& $1,201-1,600$ & 1,188 & 17 \\
Education & $1,601-2,000$ & 488 & 7 \\
& $2001+$ & 202 & 2.9 \\
& Total & 297 & 4.2 \\
& Elementary & 6,998 & 100 \\
& Junior high school & 11 & 0.2 \\
& High school & 65 & 0.9 \\
& Student & 671 & 9.6 \\
& Graduate & 2,374 & 33.9
\end{tabular}


Finally, the sample $(N=9,150)$ of a previous research (Antonopoulos et al., 2015) was also used in order to study this time the effect concerning the reasons (i.e., article characteristics) that users post (share-like) an article in social media. This time the sample included 6,998 participants with age ranging from 18 to 57 years old $(M=28.95 ; S D=9.11)$.

Only those that selected the "Daily" option were included in the final sample set (four samples with same questions), taking also into consideration an IP authentication/cross-checking process (unique IP address). Furthermore, all participants were asked to indicate if they have an account at a social network, such as Facebook, Twitter, LinkedIn, Hi5, Academia, etc. By selecting "Yes" they were included to the samples under research. Finally, those who gave inconsistent answers in the following two specific questions were also excluded from the sample. These questions were "Are you willing to pay in order to log onto a website that provides services, documents and videos that you find interesting?" and "How much money per month would you spend for access to services, documents and videos that you find interesting?".

\section{Results}

\section{Analysis on the Computer Laboratory Sample}

A repeated measures ANOVA (target of comparison: self, friends and others in general) was employed in order to test perceived influence based on the characteristic of social posting (see Table 6). Crombach $a=$ 0.711 .

Table 6

Mean Perceived Influence of the Characteristic Social Posting Across Targets of Comparison

\begin{tabular}{llll}
\hline Sample & Self & Friends & Others \\
\hline Social posting & $2.64^{*}$ & $3.09^{*}$ & $3.44^{*}$ \\
$(N=66)$ & $(1.03)$ & $(0.83)$ & $(0.73)$ \\
\hline
\end{tabular}

Notes. Mean ratings range from 1-5, higher value indicating more influence. "All significance was at $p<0.0001$. Numbers in the parentheses are standard deviations.

For the social posting (i.e., "When you read an article on a website and you notice that many users have posted it on Facebook, Twitter, or other social media do you believe that this information can affect yourself, friends and others") the results showed statistically significant differences on the level of influence $[F(2,65)=$ 25.483; $p<0.0001, \eta_{p}{ }^{2}=0.286$, power $\left.\left.=1.000\right)\right]$ with the self $(M=2.64 ; S D=1.03)$ being less influenced compared to friends $(M=3.09 ; S D=0.83)$ and others $(M=3.44 ; S D=0.73)$. Bonferroni tests on the mean values proved to be significant for all comparisons at $p<0.001$. For social posting the effect size was 0.286 explaining approximately $28.6 \%$ of the variability.

Differences on the influence of the self. In order to explore age differences in the WTPE, ANOVA was also employed taking age as an independent variable with five groups: (a) 18-19 years old (first and second year College students), (b) 20 years old (third year College students), (c) 21 years old (senior College students, one year before graduation), (d) 22-23 (after graduation), and (e) 24 years old (Master's degree students). WTPE was measured, by subtracting the influence on the self from others (others minus self). Thus, one dependent variable was created for the "social" item (see Table 7).

To examine the relationships between the variables, Pearson's correlation coefficients were used, for each variable in relation to the WTPE (others minus the self). The analysis showed that sociall and social4 were 
both negatively correlated with the WTPE ( $r=-0.242 ; p=0.05$ and $r=-0.355 ; p=0.003$ respectively). The more they believe that others are influenced more than themselves, the less they report that they choose to post something because many other have post it, and the less because it has an interesting image.

Table 7

Pearson Correlations of WTPE (Others Minus the Self)

\begin{tabular}{llll}
\hline$N=66$ & & social1 & social4 \\
\hline \multirow{2}{*}{ WTPE } & Pearson Correlation & $-0.242^{*}$ & $-0.355^{* *}$ \\
& Sig. (2-tailed) & 0.050 & 0.003 \\
\hline
\end{tabular}

Notes. ${ }^{* *}$ Correlation is significant at the 0.01 level (2-tailed); ${ }^{*}$ Correlation is significant at the 0.05 level (2-tailed).

Relationships among the variables. To examine relationships among the variables correlation coefficients were computed. The research has found $(N=66)$ that sociall, social2, social3, and social4 were positively correlated with the perceived effect on self $(r=0.294 ; p=0.017 ; r=0.262 ; p=0.034 ; r=0.289 ; p=$ $0.019 ; r=0.438 ; p<0.0001$ respectively). Hence, the more participants report that they post something because it has an interesting picture or an interesting video, or because their friends or many others have post it, the more they think that they will be influenced themselves. Also, social4 was positively correlated with the effect on friends $(r=0.256 ; p=0.038)$.

Social answers. A repeated measures $\operatorname{ANOVA}\left(F(5,65)=87.84 ; p<0.0001, \eta_{p}{ }^{2}=0.575\right.$, power $\left.=1.000\right)$ on the reasons that participants post something on line showed that the text $(M=4.29, S D=0.70)$ was the most important reported reason (with significant differences to all other reasons), video $(M=3.06, S D=1.05)$ was the second most significant reason, other reason $(M=2.62, S D=1.10)$ and interesting picture $(M=2.20, S D=$ 1.16) came next, and last were the reasons "because their friends" $(M=1.68, S D=0.84)$ or "because many others" $(M=1.60, S D=0.82)$ have done so.

Table 8

Descriptive Statistics With Answers From Questions (Sociall-6): Why Do You Usually Choose to Post an Article on Facebook, Twitter or Other Social Media?

\begin{tabular}{lll}
\hline$N=66$ & Mean & Std. Deviation \\
\hline social1 & 2.20 & 1.153 \\
social2 & 3.06 & 1.051 \\
social3 & 1.68 & 0.844 \\
social4 & 1.59 & 0.822 \\
social5 & 4.29 & 0.696 \\
social6 & 2.62 & 1.106 \\
\hline
\end{tabular}

\section{Analysis on the Mass Media Website Sample}

A repeated measures ANOVA (target of comparison: self, friends and others in general) was employed in order to test the WTPE with regard to social posting in a mass media website. The question is analyzed in Table 9 (Crombah $a=0.873$ ).

For the social posting (i.e., "When you read an article on a website and notice that many users have posted it on Facebook, Twitter, or other social media do you believe that this information can affect yourself, friends and others") the results showed statistically significant differences on the level of influence $[F(2,67)=35.808$; $p<0.0001, \eta_{p}{ }^{2}=0.348$, power $\left.\left.=1.000\right)\right]$ with the self being less influenced $(M=2.28 ; S D=1.13)$ compared to 
friends $(M=2.72 ; S D=1.04)$ and others $(M=3.16 ; S D=1.12)$. Bonferroni tests on the means were significant for all comparisons at $p<0.001$. For social posting the effect size is 0.348 explaining approximately $34.8 \%$ of the variability.

Table 9

Mean Perceived Influence on the Characteristic Social Posting Across Targets of Comparison

\begin{tabular}{llll}
\hline Sample & Self & Friends & Others \\
\hline Social posting & $2.28^{*}$ & $2.72^{*}$ & $3.16^{*}$ \\
$(N=68)$ & $(1.13)$ & $(1.04)$ & $(1.12)$ \\
\hline
\end{tabular}

Notes. Mean ratings range from 1-5, higher values indicating more influence. ${ }^{*}$ All significance was at $p<0.0001$. Numbers in the parentheses are standard deviations.

Differences on the influence of the self. In order to explore age differences in the WTPE, we have employed an ANOVA with age as an independent variable with five groups: (a) 18-25, (b) 26-33, (c) 34-41, (d) 42-49, and (e) 50-57. The last two groups (42-49, 50-57) were combined together forming a new group of 42 plus, since inadequate number of participants was available ( 5 subjects in each category). An ANOVA with independent variable the age showed significant results $(F(3,67)=4.18, p<0.01)$. Least square difference post-hoc tests showed that older participants (42 plus, $M=1.80, S D=1.47$ ) perceived a larger WTPE compared to all younger age groups (18-25, $M=0.78, S D=0.95,26-33 M=0.44, S D=0.78$, and 34-41, $M=$ $1.00, S D=0.85$ ). In the same vein, a correlation analysis showed that age (measured as a ratio variable) was positively correlated with WTPE suggesting that older participants tend to perceive that the influence will be greater on others and not on themselves $(r=0.27, p<0.03)$.

Relationships among the variables. To examine relationships among the variables correlation coefficients were extracted for each variable. We have found $(N=68)$ that social2 was positively correlated with the effect on friends and others $(r=0.275 ; p=0.023 ; r=0.273 ; p=0.024$ respectively). Hence, the more they post something with an interesting video, the more they think that their friends and others will be influenced. Correlation analysis also showed that the more the participants report the interesting picture as a reason, the more they report the interesting video as another reason $(r=0.60, p<0.01)$. Also the more they report that they post something because their friends also did, the more they report that they post it because many other users have done so $(r=0.77, p<0.01)$.

Table 10

Descriptive Statistics With Answers From Questions (social1-6): Why Do You Usually Choose to Post an Article on Facebook, Twitter or Other Social Media?

\begin{tabular}{lll}
\hline$N=68$ & Mean & Std. Deviation \\
\hline social1 & 2.69 & 1.273 \\
social2 & 2.88 & 1.179 \\
social3 & 1.75 & 0.952 \\
social4 & 1.59 & 0.918 \\
social5 & 4.34 & 0.840 \\
social6 & 2.79 & 1.322 \\
\hline
\end{tabular}

Social answers. A repeated measures ANOVA $\left(F(5,65)=63.70 ; p<0.0001, \eta_{p}{ }^{2}=0.487\right.$, power $\left.=1.000\right)$ was conducted on the reasons that participants post something on line, showed that the text $(M=4.34, S D=$ 0.84) was the most important reported reason (with significant differences to all other reasons), followed by the 
video $(M=2.88, S D=1.18)$, other reasons $(M=2.79, S D=1.32)$, and the picture $(M=2.69, S D=1.27)$. Less important proved to be the influence of the reasons "posting something because their friends" $(M=1.75, S D=$ $0.95)$ or "because many others" $(M=1.60, S D=0.92)$ have done so.

\section{Sample From All Over the World}

A repeated measures ANOVA (target of comparison: self, friends and others in general) was employed in order to test the WTPE on the characteristic social posting distributed by email and posted on Facebook. Each question is analyzed separately in Table 11 (Crombah $a=0.905$ ).

Table 11

Mean Perceived Influence on the Characteristic Social Posting Across Targets of Comparison

\begin{tabular}{llll}
\hline Sample & Self & Friends & Others \\
\hline Social posting & $2.71^{*}$ & $2.90^{*}$ & $3.05^{*}$ \\
$(N=272)$ & $(1.17)$ & $(1.11)$ & $(1.15)$ \\
\hline
\end{tabular}

Notes. Mean ratings range from 1-5, higher values indicating more influence. "All significance was at $p<0.0001$. Numbers in the parentheses are standard deviations.

For the social posting (i.e., "When you read an article on a website and notice that many users have posted it on Facebook, Twitter, or other social media do you believe that this information can affect yourself, friends and others") the results showed statistically significant differences on the level of influence $[F(2,271)=$ 25.516; $p<0.0001, \eta_{p}{ }^{2}=0.086$, power $\left.\left.=1.000\right)\right]$ with the self being less influenced $(X=2.71 ; S D=1.17)$ compared to friends $(X=2.90 ; S D=1.11)$ and others $(X=3.05 ; S D=1.15)$. Bonferroni tests on the means were significant for all comparisons at $p<0.001$. For social posting the effect size was 0.13 , explaining approximately $13 \%$ of the variability.

Differences on the influence of the self. In order to explore age differences in the WTPE, ANOVA was employed taking age as an independent variable with five groups: (a) 18-25, (b) 26-33, (c) 34-41, (d) 42-49, and (e) 50-57. WTPE was measured by subtracting the influence on the self from others (others minus self). Thus one dependent variable was created for the "social" item (see Table 12).

Table 12

Pearson Correlations of Others Minus the Self (Others-self) Across the Answers of the Question: Why Do You Usually Choose to Post an Article on Facebook, Twitter or Other Social Media?

\begin{tabular}{lll}
\hline$N=272$ & & social6 \\
\multirow{2}{*}{ WTPE } & Pearson Correlation & $0.120^{*}$ \\
& Sig. (2-tailed) & 0.048 \\
\hline
\end{tabular}

Note. ${ }^{*}$ Correlation is significant at the 0.05 level (2-tailed).

A correlational analysis showed a positive relationship between the WTPE and the other as a reason for posting something online $(r=0.12, p<0.05)$. The more participants report other as a reason for posting the more they perceive a greater WTPE for others.

Relationships among the variables. In order to examine relationships among the variables, Pearson's correlation coefficients were extracted for each variable in relation to age, Internet use, education and monthly income. Age was found to be positively correlated with the effect on self and others on the "social" variable in a negative direction $(r=-0.116 ; p<0.0001 ; r=-0.058 ; p<0.0001$ and $r=-0.079 ; p<0.0001$ respectively). Age also correlated with Internet use $(r=-0.104)$, education $(r=0.306 ; p<0.0001)$ and monthly income $(r=$ 
0.576; $p<0.0001)$. Additionally, age was negatively correlated with the effect on self and others on the "article online" variable ( $r=-0.166 ; p<0.0001 ; r=-0.099 ; p<0.0001$ and $r=-0.105 ; p<0.0001$ respectively). Finally, age was negatively correlated with the effect on self and others on the "social" variable $(r=-0.162 ; p<$ $0.0001 ; r=-0.113 ; p<0.0001$ and $r=-0.084 ; p<0.0001$ respectively).

A negative correlation between observing the source and perceived influence of the "source" to self and others was also significant $(r=0.278 ; p<0.0001$ and $r=-0.119, p<0.0001)$. Overall, when someone observes the source of the article the perceived influence on the self increases and the WTPE decreases. On the contrary, the number of users that are online at the same time in a website have found to influence self but not WTPE ( $r$ $=0.104)$. Correlational analysis showed that age was negatively related to perceived influence on self, friends and others $(r=-0.202, r=-0.206, r=-0.184$, respectively, all $p s<0.001)$. Hence, the older the participants, the less they think that they, their friends and other people will be influenced. Also, it was revealed that the more participants post something because it bears an interesting picture or video, the more they think that themselves, their friends, and others will be influenced (all $r$ s between 0.15 and $0.31 p s<0.01$ ). Similarly, the more participants report that they post something because their friends and many others have done so, the more they think that their friends and others are influenced (all $r$ s between 0.24 and $0.28 p s<0.01$ ). To examine relationships among the variables, Pearson's correlation coefficients were performed for each variable (see Table 13).

Table 13

Relationships Among the Variables

\begin{tabular}{|c|c|c|c|c|}
\hline$N=272$ & & Self & Friends & Others \\
\hline \multirow{2}{*}{ age } & Pearson Correlation & $-0.202^{* * *}$ & $-0.206^{* *}$ & $-0.184^{* *}$ \\
\hline & Sig. (2-tailed) & 0.001 & 0.001 & 0.002 \\
\hline \multirow{2}{*}{ social1 } & Pearson Correlation & $0.248^{* * *}$ & $0.318^{* * *}$ & $0.231^{* *}$ \\
\hline & Sig. (2-tailed) & 0.000 & 0.000 & 0.000 \\
\hline \multirow{2}{*}{ social2 } & Pearson Correlation & $0.222^{* * *}$ & $0.212^{* *}$ & $0.156^{*}$ \\
\hline & Sig. (2-tailed) & 0.000 & 0.000 & 0.010 \\
\hline \multirow{2}{*}{ social3 } & Pearson Correlation & $0.285^{* *}$ & $0.299^{* *}$ & $0.282^{* * *}$ \\
\hline & Sig. (2-tailed) & 0.000 & 0.000 & 0.000 \\
\hline \multirow{2}{*}{ social4 } & Pearson Correlation & $0.229^{* * *}$ & $0.253^{* *}$ & $0.245^{* *}$ \\
\hline & Sig. (2-tailed) & 0.000 & 0.000 & 0.000 \\
\hline
\end{tabular}

Notes. ${ }^{* *}$ Correlation is significant at the 0.01 level (2-tailed). ${ }^{*}$ Correlation is significant at the 0.05 level (2-tailed).

Social answers. A repeated measures $\operatorname{ANOVA}\left(F(5,271)=166.90 ; p<0.0001, \eta_{p}{ }^{2}=0.381\right.$, power $=$ $1.000)$ on the reasons that participants post something online showed, as in the previous two samples, that the text $(M=3.93, S D=1.16)$ was the most important reported reason (with significant differences to all other reasons), followed by the video $(M=2.74, S D=1.19)$ and other reasons $(M=2.63, S D=1.28)$. Next came the picture $(M=2.47, S D=1.23)$ and last were the reasons "posting something because their friends" $(M=1.97$, $S D=1.08)$ or "because many others" $(M=1.70, S D=0.98)$ have done so (see Table 14).

\section{Social Answers From All Types of Greek Media Websites}

A repeated measures ANOVA $\left(F(5,6997)=5265,309 ; p<0.0001, \eta_{p}{ }^{2}=0.429\right.$, power $\left.=1.000\right)$ on the reasons that participants post something online showed, as in the previous three samples, that the text $(M=4.02$, $S D=1.069$ ) was the most important reported reason (with significant differences to all other reasons), followed by the video $(M=2.92, S D=1.21)$, next came the picture $(M=2.59, S D=1.28)$, other reasons $(M=2.53, S D$ 
$=1.28)$ and last were the reasons "posting something because their friends" $(M=1.82, S D=1.02)$ or "because many others" $(M=1.61, S D=0.90)$ have done so (see Table 15$)$.

Table 14

Descriptive Statistics With Answers Deriving From Questions (sociall-6): Why Do You Usually Choose to Post an Article on Facebook, Twitter or Other Social Media?

\begin{tabular}{lll}
\hline Valid $N=272$ & Mean & Std. Deviation \\
\hline social1 & 2.47 & 1.230 \\
social2 & 2.74 & 1.191 \\
social3 & 1.97 & 1.086 \\
social4 & 1.70 & 0.986 \\
social5 & 3.93 & 1.160 \\
social6 & 2.63 & 1.279 \\
\hline
\end{tabular}

Table 15

Descriptive Statistics With Answers Deriving From Questions (social1-6): Why Do You Usually Choose to Post an Article on Facebook, Twitter or Other Social Media?

\begin{tabular}{lll}
\hline Valid $N=6,998$ & Mean & Std. Deviation \\
\hline social1 & 2.59 & 1.282 \\
social2 & 2.92 & 1.219 \\
social3 & 1.82 & 1.027 \\
social4 & 1.61 & 0.906 \\
social5 & 4.02 & 1.069 \\
social6 & 2.53 & 1.287 \\
\hline
\end{tabular}

\section{Discussion}

This paper expanded WTPE research to news websites by examining the role of social media metrics (i.e., shares and likes of news articles) in shaping users' opinion about the websites. Users' news sharing intention on social media was also examined. A unique aspect of the current study was the inclusion of a large and diverse sample of participants-internet users. According to the findings, the Web-Third person effect was detected in all different samples (Hypothesis 1). Consistent with Davison's initial hypothesis (1983), the patterns of results indicate that Internet users tend to report that the number of shares/likes of an article in social networks will have a greater impact on others than themselves. The results are similar to previous studies where WTPE was also found in the context of social media (Schweisberger et al., 2014; Tsay-Vogel, 2015). Also, the findings are consistent with prior work conducted by Stavrositu and Kim (2014) and Antonopoulos et al. (2015) where social media metrics were found to influence WTPE. In the present study, it has been assumed that users get affected by social media metrics (number of shares/comments) in shaping an opinion, grounded on what the other users perceive about media influence. It is argued that social web applications take advantage of natural tendency of people to follow each other (Farzan \& Brusilovsky, 2011) and reputation systems, such as shares or likes on an article, can be considered as important heuristic cues utilized when a user decides regarding the credibility and trustworthiness of online news and products (Van Der Heide, Johnson, \& Vang, 2013).

Another aspect that should be helpful in understanding the extracted results is the influence of a majority or minority source and the connection with third (or first) person effect. A majority source (what most other people believe and support) as opposed to a minority source has been found (Gardikiotis, 2010) to lead both to 
greater influence and greater perception of influence (third person perception). In the same context, Sundar and Nass (2001) suggested that readers prefer articles that appear to be selected and appreciated by many other users. It is worth mentioning that overall age was not found to be a significant factor in this study in terms of WTPE. This is in agreement with previous work (Henriksen \& Flora, 1999; Salwen \& Dupagne, 2001), where age and other demographic variables had limited effects. Although age was not a significant independent variable in determining WTPE, it was negatively correlated with it (especially in the mail and Facebook sample-participants from all over the world), that is, the older the participants the less they think that themselves, their friends, and other people will be influenced.

Regarding hypothesis H1A, one of the most striking findings was the detection of the third person effect among three groups under study: oneself, friends and others. The results showed statistically significant differences on the level of influence with the self being statistically less influenced compared to friends (ingroup) and others. It should be noted that this finding is in agreement with previous work examining TPE (Gardikiotis, 2008). Specifically, the effect size for the first sample (participants from a computer laboratory) was 0.286 with $28.6 \%$ variability explained, the effect size for the second sample (participants from a mass media website) was 0.348 with $34.8 \%$ variability and, finally, the effect size for the third sample (participants from all over the world) was 0.13 with $13 \%$ variability. From a social perspective, the current study confirms the idea that TPE may be magnified as others become more socially distant from the self-perceiver (Duck \& Mullin, 1995; Eveland et al., 1999). In other words, people tend to perceive those in outgroups to be more influenced than those who belong to their in groups. The results affirm the role of social distance corollary as a significant condition of TPE (Tewksbury, 2002; Wei \& Lo, 2007).

Another interesting finding of this study was the detection of WTPE without the presence of specific message content (Hypothesis H1B). As stated in the literature review, the term of TPE conceptualizes the idea that individuals tend to believe that other people are influenced by media messages to a larger extent than themselves (Davison, 1983). In this context, TPE seems to be stronger with the presence of a negative or controversial content (Hoffner et al., 1999; Lo \& Wei, 2002). Going beyond the typical pattern of TPE and the typical (negative) media content, the current study found the phenomenon in relation to the number of shares an article has in several social networks. In brief, this study concludes that WTPE can also be found in social media metrics, when there are no single stories and contexts. Also, it highlights the significance of the influence of others' usage and sharing behavior upon the effect (even without a specific content).

With the proliferation of Web 2.0 technologies, the advent of user-generated content (UGC) enables individuals to create their own content and share their knowledge online. Nowadays, facilities for sharing online are among the key features of a website. A significant part of this research concerns the reasons, that is, the article characteristics that drive people to share a news article on several social networks. In order to examine that question, a range of six possible answers (an interesting picture, an interesting video, my friends have posted it, many other users have posted it, the perceived interest of the text or something else) were given to respondents.

The findings presented in this study indicate that the text was the most important reported reason with significant differences to all other reasons, followed by the video variable. These results are confirmed in the three main population samples (computer laboratory, mass media website, and English sample) (Hypothesis H2). More precisely, the mean of the text variable was 4.29 concerning the first sample, 4.34 for the second sample, and 3.93 for the third sample. Regarding video, the means were 3.06, 2.88, and 2.74 for the three samples, respectively. One of the most striking findings has to do with the consistency of answers concerning 
the order of the reported reasons that drive users to share online. In all three samples the order was precisely the same, as follows: (a) text, (b) video, (c) other reasons, (d) picture, (e) friends have posted it, and (f) many others have posted it. It should be noted that a similar factor analysis was also conducted using a quite large sample of a previous research $(N=6,998)$, where WTPE was found (Antonopoulos et al., 2015). Based on these additional results, it is clearly evident that text was once again the most important reported reason for sharing online articles (mean $=4.02$ ) followed by video and in the third place picture.

As already argued, to the best of our knowledge there is relatively limited research concerning news sharing in social media, due to the fact that the majority of prior work has focused on information sharing in general. In this context, the nature of news content and some of its particular characteristics should be taken seriously into account (Lee \& Ma, 2012). Factors such as timeliness or the impact on civic agenda and public opinion distinguish news content from other types of informational content (McCombs \& Shaw, 1972; Sundar, 1999). Informativeness or simply the extent of relevant and timely information seems to be a strong motivation in predicting news sharing intention (Lee et al., 2011). According to Bro and Wallberg (2014) well-known persons/places (actors) and unusual facts (actions) seem also to be particularly important in understanding the news stories that audiences receive. Furthermore, social media users tend to prefer hard news and thus, opinion pieces over soft and general news. Another aspect that should be considered is the tendency of journalists-web editors to write in order to grab readers' attention and generate engagement. The use of declarative headlines is a common practice even if they are often wrong or misleading causing readers to believe things which are not true. Fake news articles generate much more shares and social interactions. The fact that they are engineered to attract human emotions such as curiosity, hopes and fears as well as the optimization for social media facilitate the creation of content that drives engagement (Moses, 2014). In the same vein, feedback to article may depend on the appeal of the article (Bastos, 2014). A recent study by psychologists found that misleading headlines have a significant effect on readers' memory for news articles as well as their inferential reasoning (Ecker et al., 2014). Headlines are still the primary communication method for news articles. Headlines' features such as their compact and clear nature make an immediate impression on readers and the results of the aforementioned research offer evidence that headlines affect the overall processing of information about an article (Ecker et al., 2014). All the above are associated with the text and consequently, may explain to an extent the finding that text was the most salient factor. However, news sharing in social networks is an issue that should be addressed further in future studies.

The current study also examined possible relationships of WTPE among the six (6) variables (social1-6) under study (i.e., the reasons internet users share/like an article on social media). Specifically, the analysis of the first and third sample showed that the more participants report that they post something because of a reason (it has an interesting picture, an interesting video, because their friends or many others have posted it), the more they think themselves, their friends and others will be influenced by social media metrics. In addition, in the second sample the results revealed that the more participants report that they post something because it has an interesting video, the more they think that their friends and others will be influenced. In summary, social variables 1 to 4 were found to be positively correlated with the effect (Hypothesis H1C).

\section{Conclusion}

This study extended research on the WTPE to include social media metrics and article characteristics that motivate people to share news articles in social media. Based on the conducted research the following 
conclusions can be outlined. First, WTPE can be found in social media metrics when there are no single stories and contexts and thus content is unknown (in particular, it was found across allthe tested samples). Second, the effect was more pronounced among three different social groups: self, friends and distant others. Third, text was indicated as the most salient factor regarding users' news sharing intention in social media. Fourth, the results of our analysis identified a significant relationship between Web-Third person perception and article characteristics that drive online users to post an article on social media. Finally, the study indicated that social networking services and more precisely, social media metrics should be taken seriously into consideration when designing a website due to the fact that they have an effect on users' opinion and satisfaction concerning aspects such as the degree of credibility and trustfulness of a news website.

\section{Limitations and Future Research}

Limitations of the present study include participants' prior internet and social media experience as well as the impact of different types of news content such as entertainment, sports, science or politics. Both can have a significant effect on users' perception and their news sharing intention in social media. Future research could examine whether information about other participants' use (e.g., metrics) has indeed a differential effect on the perceived influence of the content or the form of a media message.

\section{References}

Antonopoulos, N., \& Veglis, A. (2012). Technological characteristics and tools for Web media companies in Greece. Proceedings from 16th Panhellenic Conference on Informatics (PCI), Piraeus.

Antonopoulos, N., Veglis, A., Gardikiotis, A., Kotsakis, R., \& Kalliris, G. (2015). Web Third-person effect in structural aspects of the information on media websites. Computers in Human Behavior, 44, 48-58.

Banning, S. A., \& Sweetser, K. D. (2007). How much do they think it affects them and whom do they believe?: Comparing the third-person effect and credibility of blogs and traditional media. Communication Quarterly, 55, 451-466.

Barassi, V., \& Trere, E. (2012). Does Web 3.0 come after Web 2.0? Deconstructing theoretical assumptions through practice. New Media and Society, 14, 1269-1285.

Bastos, M. T. (2014). Shares, pins, and tweets. Journalism Studies, 16, 305-325.

Bro, P., \& Wallberg, F. (2014). Digital Gatekeeping. Digital Journalism, 2, 446-454.

Brosius, H. B., \& Engel, D. (1996). The causes of third-person effects: Unrealistic optimism, impersonal impact, or generalized negative attitudes towards media influence? International Journal of Public Opinion Research, 8, 142-162.

Bruns, A. (2008). Blogs, wikipedia, second life, and beyond: From production to produsage. USA: Peter Lang Publishing Inc.

Chen, S. C., Yen, D. C., \& Hwang, M. I. (2012). Factors influencing the continuance intention to the usage of Web 2.0: An empirical study. Computers in Human Behavior, 28, 933-941.

Davison, W. P. (1983). The third-person effect in communication. Public Opinion Quarterly, 47, 1-15.

Duck, J. M., \& Mullin, B. A. (1995). The perceived impact of the mass media: Reconsidering the third person effect. European Journal of Social Psychology, 25, 77-93.

Ecker, U. K. H., Lewandowsky, S., Chang, E. P., \& Pillai, R. (2014). The effects of subtle misinformation in news headlines. Journal of Experimental Psychology: Applied, 20(4), 323-335.

Eveland, W. P., Nathanson, A. I., Detenber, B. H., \& McLeod, D. M. (1999). Rethinking the social distance corollary: Perceived likelihood of exposure and the third-person perception. Communication Research, 26, 275-302.

Flanagin, A. J., \& Metzger, M. J. (2007). The role of site features, user attributes, and information verification behaviors on the perceived credibility of Web-based information. New Media and Society, 9, 319-342.

Gardikiotis, A. (2008). Group distinctiveness, political identification, and the third-person effect: Perceptions of a political campaign in the 2004 Greek National Election. Media Psychology, 11(3), 331-353.

Gardikiotis, A. (2010). Third person perception and social influence: The perception of the majority or minority influence. In S. Papastamou, M. Prodromitis, \& B. Pavlopoulos (Eds.), Social thinking, cognition and behavior: 29 Greek social psychologists re-consider their science (pp. 185-212). Pedio. 
Gerlitz, C., \& Helmond, A. (2013). The like economy: Social buttons and the data-intensive Web. New Media and Society, 15, 1348-1365.

Giannakos, M. N., Chorianopoulos, K., Giotopoulos, K., \& Vlamos, P. (2013). Using Facebook out of habit. Behaviour \& Information Technology, 32(6), 594-602.

Giomelakis, D., \& Veglis, A. (2015). Investigating search engine optimization factors in media Websites. Digital Journalism, 10, $379-400$.

Goode, L. (2009). Social news, citizen journalism and democracy. New Media and Society, 11, 1287-1305.

Habibi, M. R., Laroche, M., \& Richard, M. O. (2014). The roles of brand community and community engagement in building brand trust on social media. Computers in Human Behavior, 37, 152-161.

Henriksen, L., \& Flora, J. A. (1999). Third-person perception and children: Perceived impact of pro- and anti-smoking ads. Communication Research, 26(6), 643-665.

Hoffner, C., Buchanan, M., Anderson, J. D., Hubbs, L. A., Kamigaki, S. K., Kowalczyk, L., .., Silberg, K. J. (1999). Support for censorship of television violence: The role of the third-person effect and news exposure. Communication Research, 26, 726-742.

Jinadasa, M. P. K. (2009). Media impact on psychiatric condition and mental disorders: Qualitative analysis of media psychological perspective. Proceedings from 10th Annual Research Symposium 2009, Faculty of Graduate Studies, University of Kelaniya, Kelaniya, Sri Lanka.

John, N. A. (2012). Sharing and Web 2.0: The emergence of a keyword. New Media and Society, 15, 167-182.

Kluver, A. R. (2002). The logic of new media in international affairs. New Media and Society, 4, 499-517.

Knobloch-Westerwick, S., Sharma, N., Hansen, D. L., \& Alter, S. (2005). Impact of popularity indications on readers' selective exposure to online news. Journal of Broadcasting and Electronic Media, 49, 296-313.

Kuan, H. H., Bock, G. W., \& Vathanophas, V. (2008). Comparing the effects of Website quality on customer initial purchase and continued purchase at e-commerce Websites. Behaviour \& Information Technology, 27(1), 3-16.

Lee, C. S., \& Ma, L. (2012). News sharing in social media: The effect of gratifications and prior experience. Computers in Human Behavior, 28, 331-339.

Lee, C. S., Ma, L., \& Goh, D. H. L. (2011). Why do people share news in social media? In N. Zhong, V. Callaghan, A. Ghorbani, \& B. Hu (Eds.), Active Media Technology (pp. 129-140). Berlin: Springer.

Lee, E. J. (2012). That's not the way it is: How user-generated comments on the news affect perceived media bias. Journal of Computer-Mediated Communication, 18, 32-45.

Leung, L. (2013). Generational differences in content generation in social media: The roles of the gratifications sought and of narcissism. Computers in Human Behavior, 29, 997-1006.

Li, X. (2008). Third-person effect, optimistic bias, and sufficiency resource in Internet use. Journal of Communication, 58, 568-587.

Lo, V. H., \& Wei, R. (2002). Third-person effect, gender, and pornography on the Internet. Journal of Broadcasting and Electronic Media, 46(1), 13-33.

McCombs, M. E., \& Shaw, D. L. (1972). The agenda-setting function of mass media. Public Opinion Quarterly, 36, $176-187$.

McMillan, S. (2002). Exploring models of interactivity from multiple research traditions: Users, documents, and systems. In Handbook of New Media (pp. 162-182). London: Sage.

Meyrick, J. (2001). Forget the "Blood and Gore": An alternative message strategy to help adolescents avoid cigarette smoking. Health Education, 101(3), 99-107.

Neuman, W., Just, M., \& Crigler, A. (1992). Common knowledge: News and the construction of political meaning. Chicago: University of Chicago Press.

O'Reilly, T. (2005). What is web 2.0: Design patterns and business models for the next generation software. Retrieved from http://www.oreilly.com/pub/a/web2/archive/what-is-web-20.html

Papacharissi, Z., \& Rubin, A. M. (2000). Predictors of Internet use. Journal of Broadcasting and Electronic Media, 44, 175-196.

Perloff, R. M. (1999). The third person effect: A critical review and synthesis. Media Psychology, 1, 353-378.

Rocha, A. (2012). Framework for a global quality evaluation of a website. Online Information Review, 36, 374-382.

Rucinski, D., \& Salmon, C. T. (1990). The "Other" as the vulnerable voter: A study of the third-person effect in the 1988 U.S. Presidential Campaign. International Journal of Public Opinion Research, 2(4), 345-368.

Salwen, M. B., \& Dupagne, M. (2001). Third-person perception of television violence: The role of self-perceived knowledge. Media Psychology, 3, 211-236. 
Schweisberger, V., Billinson, J., \& Chock, T. M. (2014). Facebook, the third-person effect, and the differential impact hypothesis. Journal of Computer-Mediated Communication, 19, 403-413.

Stavrositu, C. D., \& Kim, J. (2014). Social media metrics: Third-person perceptions of health information. Computers in Human Behavior, 35, 61-67.

Sundar, S. S. (1999). Exploring receivers' criteria for perception of print and online news. Journalism and Mass Communication Quarterly, 76, 373-386.

Sundar, S. S., \& Nass, C. (2001). Conceptualizing sources in online news. Journal of Communication, 51(1), 52-72.

Tewksbury, D. (2002). The role of comparison group size in the third-person effect. International Journal of Public Opinion Research, 14, 247-263.

Tiedge, J. T., Silverblatt, A., Havice, M. J., \& Rosenfeld, R. (1991). Discrepancy between perceived first-person and perceived third-person mass media effects. Journalism and Mass Communication Quarterly, 68(1-2), 141-154.

Tsay-Vogel, M. (2015). Me versus them: Third-person effects among Facebook users. New Media and Society, 18(9), $1956-1972$.

Van Der Heide, B., Johnson, B. K., \& Vang, M. H. (2013). The effects of product photographs and reputation systems on consumer behavior and product cost on Ebay. Computers in Human Behavior, 29(3), 570-576.

Wei, H. L., Lin, K. Y., Lu, H. P., \& Chuang, I. H. (2015). Understanding the intentions of users to "Stick" to social networking sites: A case study in Taiwan. Behaviour \& Information Technology, 34(2), 151-162.

Wei, R., \& Lo, V. H. (2007). The third-person effects of political attack ads in the 2004 U.S. Presidential Election. Media Psychology, 9, 367-388.

Westerman, D., Spence, P. R., \& Van Der Heide, B. (2012). A social network as information: The effect of system generated reports of connectedness on credibility on Twitter. Computers in Human Behavior, 28, 199-206.

Yoo, J. J. Y. (2012). A qualitative analysis of how and why people use SNSs: A cross-cultural comparison of Korea and the U.S. Journalism and Mass Communication, 2(6), 701-716.

Yu, S. Y. (2016). Online social support and use of SNSs among college students: Relationship to online and offline social skills. Journalism and Mass Communication, 6(6), 313-322.

Zhang, J., \& Daugherty, T. (2009). Third-person effect and social networking: Implications for online marketing and word-of-mouth communication. American Journal of Business, 24, 53-64. 